\title{
The adsorptive properties of oxidized activated carbons and their applications as carbon paste electrode modifiers
}

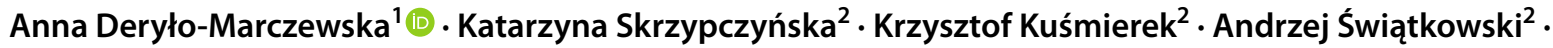 \\ Małgorzata Zienkiewicz-Strzałka'
}

Received: 30 November 2018 / Revised: 15 January 2019 / Accepted: 18 January 2019 / Published online: 25 January 2019

(c) The Author(s) 2019

\begin{abstract}
The adsorptive properties of the Organosorb-10 activated carbons treated with different ozone doses (15 and 45 min) and their applications as carbon paste electrode (CPE) modifiers have been studied. As a target organic contaminant the 4-chlorophenol (4-CP) has been selected. Both the physical and chemical properties of the activated carbon surface were characterized and the results show only low changes in porous structure of the oxidized activated carbons but significant changes in their surface chemistry. The adsorption isotherms of 4-CP on the activated carbons were analyzed using the Langmuir, Freundlich and Sips isotherm models. The equilibrium data followed the Langmuir isotherm. The activated carbons prepared by ozonation presented lower 4-CP adsorption than the unmodified adsorbent. Introduction of oxygen functional groups decreased their adsorption properties. The modified CPEs were prepared by mixing graphite powder with the unmodified and oxidized activated carbons $(2.5 \%, 5 \%$ and $10 \%$ wt. content) and used for cyclic voltammetry measurements in 4-CP solutions of different concentrations. The measured peak currents were strongly dependent on oxidation of activated carbons and correlated with the 4-CP adsorption efficiency.
\end{abstract}

Keywords 4-Chlorophenol - Adsorption - Carbon paste electrode

\section{Introduction}

Due to their unique physical and chemical properties, activated carbons have found many applications. They are widely used as powerful adsorbents for water and gases purification (Dąbrowski et al. 2005; Foo and Hameed 2010; Yagub et al. 2014), as catalysts and catalyst supports (Rodriguez-Reinoso 1998), in medicine, in electrochemistry as supercapacitors (Jian et al. 2016; Chen et al. 2017) or electrodes (Švancara et al. 2001; Zima et al. 2009; Zhang et al. 2016) and in many other areas.

Among the carbon-based electrodes, the carbon paste electrodes (CPEs) - a mixture of graphite powder and nonelectrolytic organic liquid as a binder-play an important role. These electrodes are cheap, simple to make, moreover

Anna Deryło-Marczewska

annad@hektor.umcs.lublin.pl

1 Faculty of Chemistry, M. Curie-Skłodowska University, 20-031 Lublin, Poland

2 Institute of Chemistry, Military University of Technology, 00-908 Warszawa, Poland they can be easily modified to improve their electrochemical properties. Generally, the modification consists in adding a small amount (up to $30 \% \mathrm{~m} / \mathrm{m}$ ) of the third component to the graphite/organic liquid mixture. Among various modifiers the chemical compounds and analytical reagents, ionexchangers, humic substances, silica and silica-containing matrices, clay minerals as well as carbonaceous materials are used (Švancara et al. 2001; Zima et al. 2009). The last group of modifiers includes, among others carbon nanotubes (Wong et al. 2015; Ghaedi et al. 2017), carbon blacks (Kuśmierek et al. 2015; Skrzypczyńska et al. 2016), carbon molecular sieves (Skrzypczyńska et al. 2016), graphene (Li et al. 2011; Parvin 2011; Zaidi 2013; Wong et al. 2015; Smarzewska et al. 2016) and activated carbons (Kuśmierek et al. 2015, 2017; Skrzypczyńska et al. 2016). Similar results (improving the recorded currents) were also obtained for other modified carbon electrodes (Jesionowski et al. 2014a, b).

In this work, the adsorptive properties of activated carbons treated with different ozone doses and their applications as carbon paste electrode modifiers have been studied. As a target organic pollutant 4-chlorophenol (4-CP) has been selected. The effect of adsorbent surface chemistry 
on adsorption of phenolic compounds has been studied and quite well described in the literature, while, to the best of our knowledge, there are no reports on the effect of surface chemistry of activated carbons used as electrode modifiers on their electrochemical properties.

\section{Experimental}

\subsection{Materials and apparatus}

The 4-chlorophenol ( $\geq 99 \%)$ was purchased from SigmaAldrich (USA). All other chemicals used were of analytical grade and were obtained from Avantor Performance (Poland). Carbon paste electrode components-the graphite powder $(<45 \mu \mathrm{m})$ was from Sigma-Aldrich (USA), while the mineral oil was received from Fluka (Switzerland). The adsorbent samples were prepared from the Organosorb-10 activated carbon (Desotec, Belgium) which was demineralized with concentrated hydrofluoric and hydrochloric acids. So treated activated carbon (OS-NM) was oxidized with ozone at $25^{\circ} \mathrm{C}$ in a fixed bed reactor loaded with $2 \mathrm{~g}$ of carbon under a constant ozone flow of $15 \mathrm{dm}^{3} / \mathrm{min}$ (Hailea HLO-820A ozone generator, China). Two different exposure times were used-15 $\mathrm{min}$ (OS-O3-15) and $45 \mathrm{~min}$ (OS-O3-45), respectively.

The structural properties of the activated carbon samples were characterized using low-temperature $\mathrm{N}_{2}$ adsorption-desorption isotherms (ASAP 2010, Micromeritics, USA). The specific surface area $\left(\mathrm{S}_{\mathrm{BET}}\right)$ was calculated by using BET method, the total pore volume $\left(\mathrm{V}_{\mathrm{t}}\right)$ was obtained from the amount of nitrogen adsorbed at $\mathrm{P} / \mathrm{P}_{0}=0.99$, the pore volume of micropores $\left(\mathrm{V}_{\mathrm{mi}}\right)$ was estimated from t-plot method. The pore volume of mesopores $\left(\mathrm{V}_{\mathrm{me}}\right)$ was calculated from the difference of both values. For characterization of carbon materials the other techniques were also used: scanning electron microscope (SEM-EDS, LEO 1430VP, Electron Microscopy Ltd., UK), thermogravimetry (TGDTA/DSC, STA 449 Jupiter F1, Netzsch, Germany) and the X-ray photoelectron spectroscopy (XPS, Multi-chamber UHV Analytical System, Prevac (2009) with the hemispherical analyzer Scienta R4000). During XPS analysis the monochromatic $450 \mathrm{~W} \mathrm{Al} \mathrm{K \alpha}$ radiation from high-intensity source MX-650 (1486.6 eV Gammadata Scienta) was applied. The average depth of analysis was approximately $5 \mathrm{~nm}$. The data processing and high-resolution deconvolution of $\mathrm{C} 1 \mathrm{~s}$ and O1s peaks were done by CasaXPS software.

\subsection{Adsorption procedure}

All the adsorption experiments were carried out at $25^{\circ} \mathrm{C}$ in Erlenmeyer flasks filled with $0.04 \mathrm{~L}$ of 4-chlorophenol solutions (the initial concentration of 4-CP was in the range of $0.25-2.0 \mathrm{mmol} / \mathrm{L})$. Appropriate amounts of adsorbent $(20 \mathrm{mg})$ were added and the solutions were agitated at $100 \mathrm{rpm}$ for $8 \mathrm{~h}$. Then the mixtures were filtered through a filter paper and the obtained filtrates were analyzed for 4-CP concentration $\left(C_{\mathrm{e}}\right)$ using UV-Vis spectrophotometry (Varian Carry 3E, USA). The amount of 4-CP adsorbed at equilibrium per unit mass of activated carbon $\left(q_{\mathrm{e}}\right)$ was calculated using the following formula:

$q_{\mathrm{e}}=\frac{\left(C_{0}-C_{\mathrm{e}}\right) V}{m}$

where: $C_{0}(\mathrm{mmol} / \mathrm{L})$ is the initial 4-CP concentration, $C_{\mathrm{e}}$ $(\mathrm{mmol} / \mathrm{L})$ is the equilibrium 4-CP concentration, $m(\mathrm{~g})$ is the mass of the adsorbent used and $V(\mathrm{~L})$ is the solution volume.

The experiments were carried out in duplicate, and the data obtained were used for analysis.

\subsection{Electrochemistry}

The electrochemical measurements were conducted using an Auto-Lab apparatus (PGSTAT 20, EcoChemie B.V., The Netherlands) in a three-electrode configuration system: carbon paste electrode (as a working electrode), SCEsaturated calomel electrode (as a reference electrode) and platinum wire (as a counter electrode). The carbon paste electrodes were prepared according to the previously described procedure (Skrzypczyńska et al. 2016). The bare (graphite) electrode as well as the CPEs containing 2.5\%, $5 \%$ and $10 \%$ by mass of all of the activated carbon samples were prepared and tested.

\section{Results and discussion}

\subsection{Activated carbons characterization}

The specific surface areas of the activated carbon samples were determined from the nitrogen adsorption-desorption isotherms at $77.4 \mathrm{~K}$ (Fig. 1). The values of $S_{\mathrm{BET}}$ as well as micropore and mesopore volumes are given in Table 1 . In order to characterize the surface chemistry of the activated carbon samples (oxygen content), analyses were performed by SEM/EDS, TG and by standard neutralization with $0.1 \mathrm{~mol} / \mathrm{L} \mathrm{NaOH}$ solution $(\mathrm{NaOH}$ uptake indicating changes in acid properties) (Table 2). Results of samples surface analyses by XPS are presented in Fig. 2 as well in Tables 3 and 4.

The XPS analysis was applied for obtaining quantitative and chemical state information from the surface of the carbon materials. The major signals observed in XPS spectra were identified as $\mathrm{C} 1 \mathrm{~s}$ and $\mathrm{O} 1 \mathrm{~s}$ signals with the peak position at $284.7 \mathrm{eV}$ and $532-533 \mathrm{eV}$ respectively. The general atomic concentration (\%at) of oxygen increases from 3.6 to $5.8 \%$ and 


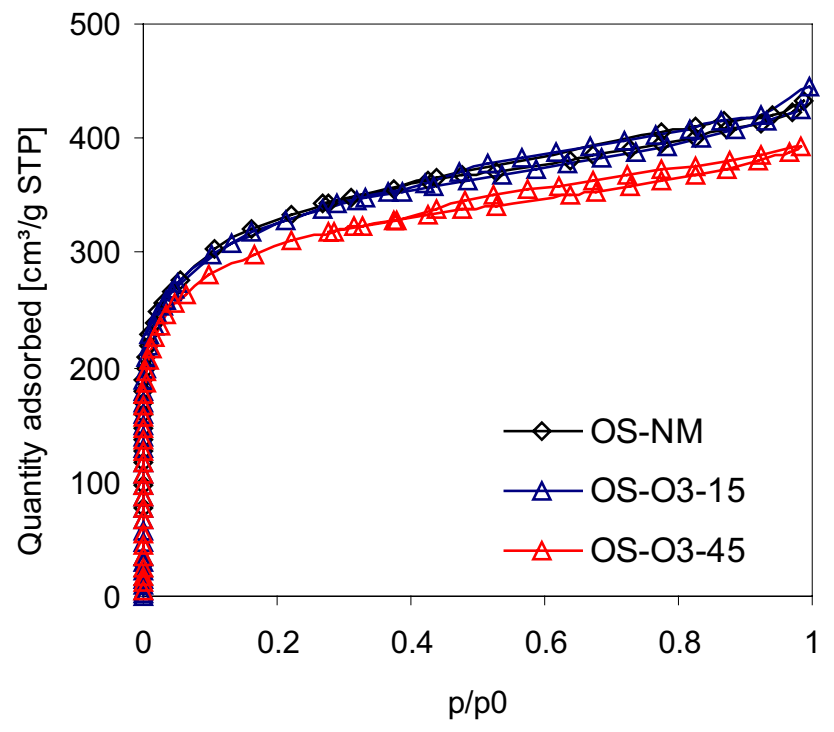

Fig. 1 The $\mathrm{N}_{2}$ adsorption-desorption isotherms of the activated carbons at $77.4 \mathrm{~K}$

Table 1 Porous structure of the activated carbons

\begin{tabular}{lllll}
\hline Activated carbon & $S_{\text {BET }}\left(\mathrm{m}^{2} / \mathrm{g}\right)$ & $V_{\mathrm{t}}\left(\mathrm{cm}^{3} / \mathrm{g}\right)$ & $V_{\mathrm{mi}}\left(\mathrm{cm}^{3} / \mathrm{g}\right)$ & $V_{\text {me }}\left(\mathrm{cm}^{3} / \mathrm{g}\right)$ \\
\hline OS-NM & 1138 & 0.549 & 0.358 & 0.191 \\
OS-O3-15 & 1129 & 0.542 & 0.353 & 0.189 \\
OS-O3-45 & 1055 & 0.491 & 0.340 & 0.151 \\
\hline
\end{tabular}

Table 2 Chemical properties of the activated carbons

\begin{tabular}{|c|c|c|c|c|}
\hline \multirow[t]{2}{*}{ Activated carbon } & \multicolumn{2}{|c|}{ Oxygen (EDS) } & \multirow{2}{*}{$\begin{array}{l}\text { Weight loss (TG) } \\
180-450{ }^{\circ} \mathrm{C}(\% \\
\text { mass })\end{array}$} & \multirow{2}{*}{$\begin{array}{l}\mathrm{NaOH} \\
\text { uptake } \\
(\mathrm{mmol} / \mathrm{g})\end{array}$} \\
\hline & (\% at.) & (\% mass) & & \\
\hline OS-NM & 2.88 & 3.74 & 0.94 & 0.399 \\
\hline OS-O3-15 & 5.66 & 7.04 & 1.77 & 0.966 \\
\hline OS-O3-45 & 6.22 & 8.42 & 2.19 & 1.391 \\
\hline
\end{tabular}

7.13\% for OS-NM, OS-15 and OS-45 samples respectively. Thus, the atomic concentration of carbon is $95.9 \%, 93.7 \%$ and $92.3 \%$ for OS-NM, OS-15 and OS-45 samples, respectively. The increase of oxygen content reflects changes of the carbon surface during the oxidation process.

The high resolution XPS spectra illustrate the chemical states of carbon and oxygen atoms as $\mathrm{C} 1 \mathrm{~S}$ and $\mathrm{O} 1 \mathrm{~s}$ respectively. The $\mathrm{C} 1 \mathrm{~s}$ and $\mathrm{O} 1 \mathrm{~s}$ regions from three carbon materials are shown in Fig. 2a, b. The C1s peak has been deconvoluted into four Lorentzian peaks with binding energies at approximately $284.7 \mathrm{eV}, 285.4 \mathrm{eV}, 286.0 \mathrm{eV}$ and $286.5 \mathrm{eV}$ and marked as C 1sA, C 1sB, C 1sC, C 1sD features. In this case, the observed binding energies for the extracted components depend on the specific functional groups located on the carbon surface. Moreover, the intensity of the core-level signals can be proportional to the atoms density. The first C1sA signal with the lowest binding energies $(284.73 \mathrm{eV}$, $284.12 \mathrm{eV}$ and $284.69 \mathrm{eV}$ for OS-NM, OS-15 and OS-45 samples respectively) can be assigned as carbon-carbon interactions. In details the binding energy values from $284 \mathrm{eV}$ to $285.0 \mathrm{eV}$ can specify the sp3 and sp2 bonded carbons state typical for graphitic carbons and $\mathrm{C}=\mathrm{C}, \mathrm{C}-\mathrm{C}$ and $\mathrm{C}-\mathrm{H}$ species (Polovina et al. 1997; Gai et al. 1989). In all cases, the C1sA signals are the strongest what suggest the $\mathrm{C}-\mathrm{C}$ bonds are dominant in the investigated carbon layer. The $\mathrm{C} 1 \mathrm{sB}$ signals with the position of binding energy of $285.56 \mathrm{eV}, 285.46 \mathrm{eV}$ and $285.42 \mathrm{eV}$ for investigated samples were shifted by more than $0.7 \mathrm{eV}$ from the position of first $\mathrm{C} 1 \mathrm{sA}$ signal. The $\mathrm{C} 1 \mathrm{sB}$ components are assigned to the $\mathrm{C}$ atoms directly bonded with the $\mathrm{O}$ atoms from hydroxyl groups $(\mathrm{C}-\mathrm{OH})$ groups (Stankovich et al. 2007; Mattevi et al. 2009). The amount of carbon-hydroxyl interactions decrease significantly during the oxidation process. The atomic concentration of $\mathrm{C} 1 \mathrm{sB}$ peaks is the greatest for OS-NM sample (5.6\%) and the lowest for the OS-45 sample (1.6\%). At the same time, the amount of carbonyl $\mathrm{C}=\mathrm{O}$ groups increases significantly. The atomic concentration (\%at) of $\mathrm{C} 1 \mathrm{sD}$ peaks (typical for carbons in carbonyl groups) increases from 6.3 to $10.5 \%$ and finally to $11.1 \%$ for OS-NM, OS-15 an OS-45 samples, respectively. The amount of the components at $\sim 286.0 \mathrm{eV}$ [attributed to epoxide or ether groups $(\mathrm{C}-\mathrm{O}-\mathrm{C})]$ are very similar for all samples.

The O1s peak is a result of the imposition of five component peaks. First O1sA signal is typical for oxygen in oxide form. Due to the chemistry of the carbon surface, this type of oxygen interaction is not considered, it is not meaningful in these studies. The $\mathrm{C} 1 \mathrm{sB}$ signals with the position of $531.01 \mathrm{eV}, 531.09 \mathrm{eV}$, and $531.02 \mathrm{eV}$ can be assigned as oxygen-carbon interaction according to carbonyl $\mathrm{O}=\mathrm{C}$ and carboxylic species. The atomic concentration of this type of functional groups increases considerably for oxidized samples. The atomic concentration of carbonyl groups increases from 34.12 to $49.0 \%$ and finally to $59.7 \%$ for OS-NM, OS-15 and OS-45 samples, respectively. Moreover, decreasing of the hydroxyl groups ( $\mathrm{C} 1 \mathrm{sC}$ and $\mathrm{C} 1 \mathrm{sD}$ signals) was observed. Such phenomenon was confirmed previously by high-resolution core level analysis of carbon atoms.

The results show only small changes in the porous structure of the oxidized activated carbons but significant changes in their surface chemistry. The ozone treatment decreased the specific surface area, $S_{\mathrm{BET}}$, of the carbons; this reduction as well as the increase in oxidation efficiency was dependent on the duration of the modification. Modification in a shorter time (15 $\mathrm{min}$ ) changes slightly the porous structure of activated carbon, while increase of time to 45 min gives a pronounced effect (greater decrease of porous structure parameters). However, these changes are not very large. 

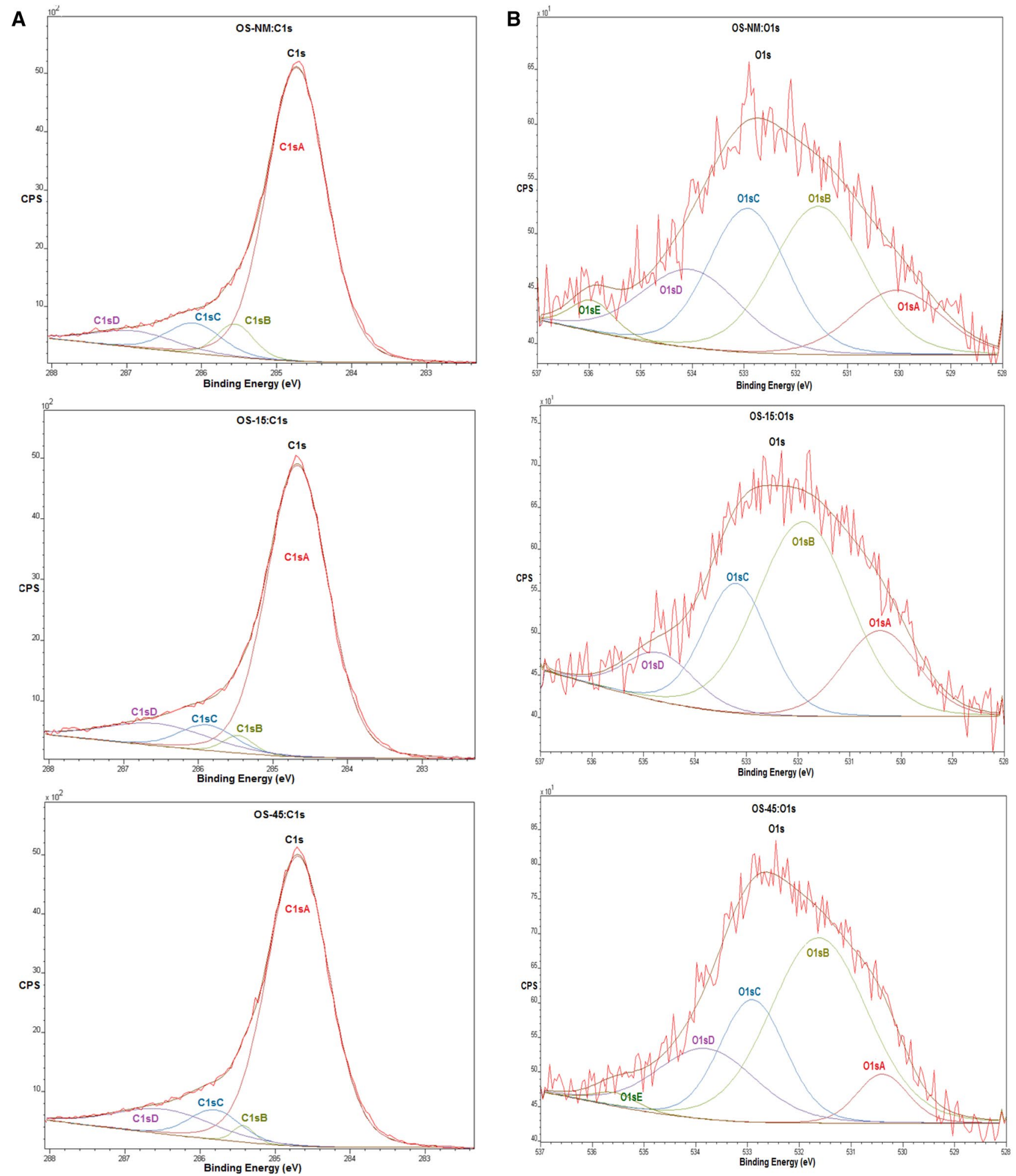

Fig. 2 a High-resolution XPS scan spectra over C1s, b High-resolution XPS scan spectra over O1s peaks

In the case of surface chemistry, the situation is different. Oxidation even for a short time (15 min) gives significant changes in the chemistry of the carbon surface, while the extension of the process to 45 min already causes a smaller change, although still quite significant. Similar effects were observed in other papers (Valdes et al. 2002). 
Table 3 Properties of $\mathrm{C} 1 \mathrm{~s}$ peaks from high resolution XPS spectra analysis and their assignment

\begin{tabular}{|c|c|c|c|c|c|c|c|}
\hline \multirow[t]{2}{*}{ Peak } & \multicolumn{2}{|c|}{ OS-NM (C 95.9\%at. $)^{\mathrm{a}}$} & \multicolumn{2}{|c|}{ OS-15 (C 93.7\%at.) ${ }^{\mathrm{a}}$} & \multicolumn{2}{|c|}{ OS-45 (C 92.3\% at.) ${ }^{\mathrm{a}}$} & \multirow[t]{2}{*}{ Binding assignation } \\
\hline & $\mathrm{BE}, \mathrm{eV}$ & At. conc., $\%^{\mathrm{b}}$ & $\mathrm{BE}, \mathrm{eV}$ & At. conc., $\%^{\mathrm{b}}$ & $\mathrm{BE}, \mathrm{eV}$ & At. conc., $\%^{\text {b }}$ & \\
\hline A & 284.73 & 80.50 & 284.67 & 80.60 & 284.69 & 80.50 & $\mathrm{C} \mathrm{sp}{ }^{3} \mathrm{C}-\mathrm{C} \mathrm{C}-\mathrm{H}$ \\
\hline B & 285.56 & 5.60 & 285.46 & 2.40 & 285.42 & 1.60 & $\mathrm{C}-\mathrm{OH}$ \\
\hline $\mathrm{C}$ & 285.10 & 7.60 & 285.89 & 6.50 & 285.81 & 6.80 & $\mathrm{C}-\mathrm{O}-\mathrm{C}$ \\
\hline D & 286.91 & 6.30 & 286.56 & 10.50 & 286.50 & 11.10 & $\mathrm{C}=\mathrm{O}$ \\
\hline
\end{tabular}

${ }^{a}$ Initial XPS surface atomic percentages calculated using the general C1s peak area from XPS survey scan

${ }^{\mathrm{b}}$ Atomic concentration of the detailed $\mathrm{C} 1$ s chemical states from high-resolution XPS spectra

Table 4 Properties of O1s peaks from high resolution analysis and their assignment

\begin{tabular}{|c|c|c|c|c|c|c|c|}
\hline \multirow[t]{2}{*}{ Peak } & \multicolumn{2}{|c|}{ OS-NM (O 3.6\%at. $)^{\mathrm{a}}$} & \multicolumn{2}{|c|}{ OS-15 (O 5.8\%at. $)^{\mathrm{a}}$} & \multicolumn{2}{|c|}{ OS-45 (O 7.13\%at.) $)^{\mathrm{a}}$} & \multirow[t]{2}{*}{ Binding assignation } \\
\hline & $\mathrm{BE}, \mathrm{eV}$ & at. conc., $\%^{\mathrm{b}}$ & $\mathrm{BE}, \mathrm{eV}$ & at. conc., $\%^{\mathrm{b}}$ & $\mathrm{BE}, \mathrm{eV}$ & at. conc., $\%^{\text {b }}$ & \\
\hline A & 530.04 & 14.44 & 530.41 & 17.40 & 530.40 & 6.80 & $\mathrm{O}$ (oxides) \\
\hline $\mathrm{B}$ & 531.01 & 34.12 & 531.09 & 49.00 & 531.02 & 59.70 & $\mathrm{O}=\mathrm{C}$ (carbonyl and carboxylic groups) \\
\hline $\mathrm{C}$ & 532.93 & 28.40 & 533.20 & 23.20 & 532.91 & 22.40 & $\mathrm{O}-\mathrm{C}$ (ether and hydroxyl groups bonded to aliphatics) \\
\hline $\mathrm{D}$ & 534.04 & 19.61 & 534.70 & 9.30 & 533.8 & 9.40 & $\mathrm{O}-\mathrm{C}$ (ether and hydroxyl groups bonded to aromatics) \\
\hline $\mathrm{E}$ & 535.94 & 3.44 & 537.11 & 1.20 & 535.56 & 1.70 & adsorbed water/oxygen, sub monolayer \\
\hline
\end{tabular}

${ }^{a}$ Initial XPS surface atomic percentages calculated from general O1s peak area from XPS survey scan

${ }^{\mathrm{b}}$ Atomic concentration of the detailed O1s chemical states from high-resolution XPS spectraD

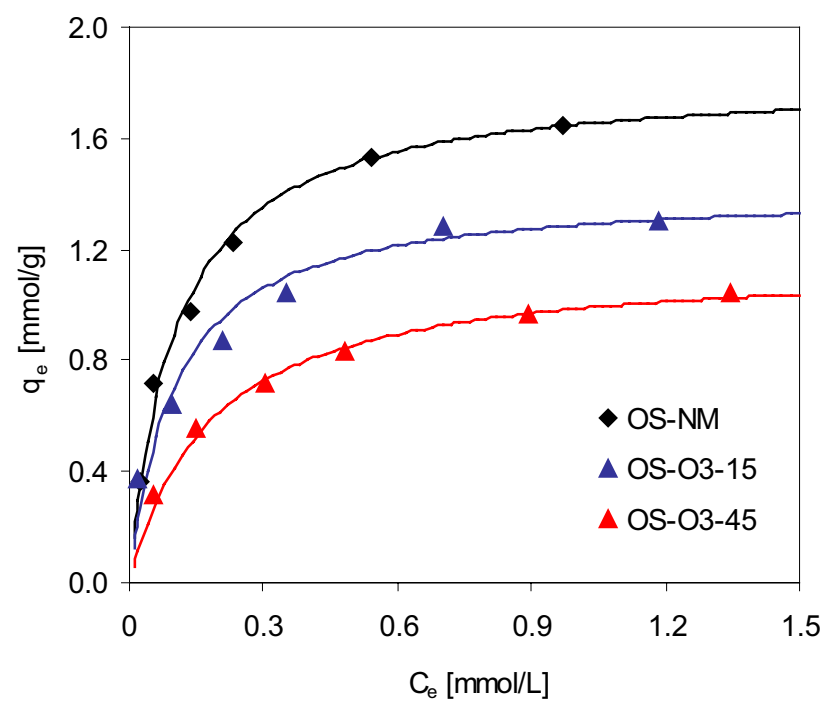

Fig. 3 Adsorption isotherms of 4-CP on the activated carbons

\subsection{Adsorption studies}

The adsorption isotherms of 4-CP from aqueous solutions onto the activated carbons are presented in Fig. 3. As can be seen, the oxidation process influences strongly the adsorption effectiveness; the higher number of oxygen surface groups the lower adsorption value. For better interpretation of the results, the experimental data for 4-CP adsorption were analyzed using the Langmuir (2), Freundlich (3) and the three-parameter Sips (4) isotherm equations (Hamdaoui and Naffrechoux 2007):

$$
\begin{aligned}
& q_{\mathrm{e}}=\frac{q_{\mathrm{m}} b C_{\mathrm{e}}}{1+b C_{\mathrm{e}}} \\
& q_{\mathrm{e}}=K_{\mathrm{F}} C_{\mathrm{e}}^{1 / \mathrm{n}} \\
& q_{\mathrm{e}}=\frac{q_{\mathrm{mS}} K_{\mathrm{S}} C_{\mathrm{e}}{ }^{m}}{1+K_{\mathrm{S}} C_{\mathrm{e}}^{m}}
\end{aligned}
$$

where: $q_{\mathrm{m}}(\mathrm{mmol} / \mathrm{L})$ and $b(\mathrm{~L} / \mathrm{mmol})$ are the Langmuir constants related to the maximum adsorption capacity and adsorption energy, respectively; $K_{\mathrm{F}}\left((\mathrm{mmol} / \mathrm{g})(\mathrm{L} / \mathrm{mmol})^{1 / \mathrm{n}}\right)$ and $n$ are the Freundlich constants related to the adsorption capacity and adsorption intensity, respectively; $q_{\mathrm{ms}}$ $(\mathrm{mmol} / \mathrm{g})$ is the Sips adsorption capacity, while $K_{\mathrm{S}}(\mathrm{L} / \mathrm{mg})$ and $m$ are the Sips model constants. All theoretical isotherm parameters were evaluated by non-linear regression (OriginPro 7.5 software) and are listed in Table 5. A high value of the correlation coefficient indicates better agreement between experimental and predicted data using the Langmuir $\left(R^{2} \geq 0.990\right)$ equation than the Freundlich $\left(R^{2} \geq 0.948\right)$ and Sips $\left(R^{2} \geq 0.981\right)$ isotherm models.

The adsorption of phenol and its derivatives (including 4-CP) on activated carbons from aqueous solutions was the subject of many research (Dąbrowski et al. 2005; Hamdaoui and Naffrechoux 2007; Hameed et al. 2008; LorencGrabowska et al. 2010; Deryło-Marczewska et al. 2011; Kuśmierek and Świątkowski 2015; Kuśmierek et al. 2017). This process occurs as a result of $\pi-\pi$ type dispersive adsorbate-adsorbent interactions, the formation of hydrogen bonds 
Table 5 The Langmuir, Freundlich and Sips isotherm equation parameters for adsorption of 4-CP on the activated carbons

\begin{tabular}{lllll}
\hline Adsorption model & Parameter & OS-NM & OS-O3-15 & OS-O3-45 \\
\hline Langmuir & $q_{\mathrm{m}}(\mathrm{mmol} / \mathrm{g})$ & 1.792 & 1.403 & 1.141 \\
& $b(\mathrm{~L} / \mathrm{mmol})$ & 9.991 & 9.635 & 6.248 \\
\multirow{3}{*}{ Freundlich } & $R^{2}$ & 0.990 & 0.990 & 0.991 \\
& $K_{\mathrm{F}}[(\mathrm{mmol} / \mathrm{g})$ & 1.774 & 1.327 & 0.992 \\
& $\left.(\mathrm{~L} / \mathrm{mmol})^{1 / \mathrm{n}}\right]$ & & & \\
\multirow{4}{*}{ Sips } & $n$ & 3.115 & 3.533 & 3.175 \\
& $R^{2}$ & 0.948 & 0.968 & 0.969 \\
& $q_{\mathrm{mS}}(\mathrm{mmol} / \mathrm{g})$ & 2.164 & 1.851 & 1.322 \\
& $K_{\mathrm{S}}(\mathrm{L} / \mathrm{mmol})$ & 3.514 & 2.354 & 2.979 \\
& $m$ & 0.714 & 0.586 & 0.756 \\
& $R^{2}$ & 0.988 & 0.986 & 0.981 \\
\hline
\end{tabular}

and/or acceptor-donor complexes (Salame and Bandosz 2003; Lorenc-Grabowska et al. 2010; Deryło-Marczewska et al. 2011). It is well known, that the adsorption of organic compounds on the activated carbons depends on their porosity including surface area, pore volume, and pore size distribution as well as on their surface chemistry. The calculated parameters related to the adsorption capacity $\left(q_{\mathrm{m}}, K_{\mathrm{F}}\right.$, and $q_{\mathrm{mS}}$ ) decrease in the order OS-NM $>$ OS-O3-15>OS-O345. 4-CP was adsorbed better on the non-oxidized activated carbon than on the OS-O3-15 and OS-O3-45 materials. This fact is closely correlated with the reduction of the specific surface area of activated carbons as well as mainly with the increase in the content of acidic oxygen groups on the adsorbent surface. The oxygen surface groups decrease the surface hydrophobicity and the $\pi$-electron density in the graphene layers and consequently reduce the dispersive adsorption potential of the activated carbon (Salame and Bandosz 2003; Álvarez et al. 2005; Deryło-Marczewska et al. 2011).

\subsection{Electrochemical studies}

The electrochemical behavior of the prepared CPEs was investigated using cyclic voltammetry (CV). In the first stage, optimization studies have been conducted. These investigations were performed using the electrodes containing the highest modifier additive (10\%).

For the purpose of determining the electroactive surface area of all electrodes the electrochemical behavior of potassium ferrocyanide in $1.0 \mathrm{~mol} / \mathrm{L} \mathrm{KCl}$ supporting electrolyte was studied. The cyclic voltammograms of $2.0 \mathrm{mmol} / \mathrm{L}$ $\mathrm{Fe}(\mathrm{CN})_{6}{ }^{3-} / \mathrm{Fe}(\mathrm{CN})_{6}{ }^{4-}$ in $0.1 \mathrm{~mol} / \mathrm{L} \mathrm{KCl}$ are presented in Fig. 4 (scan rate $100 \mathrm{mV} / \mathrm{s}$ ). The peak current for a reversible process is described by the Randles-Sevcik Eq. (5):

$I_{\mathrm{p}}=2.69 \times 10^{5} A D^{1 / 2} n^{3 / 2} \nu^{1 / 2} C$

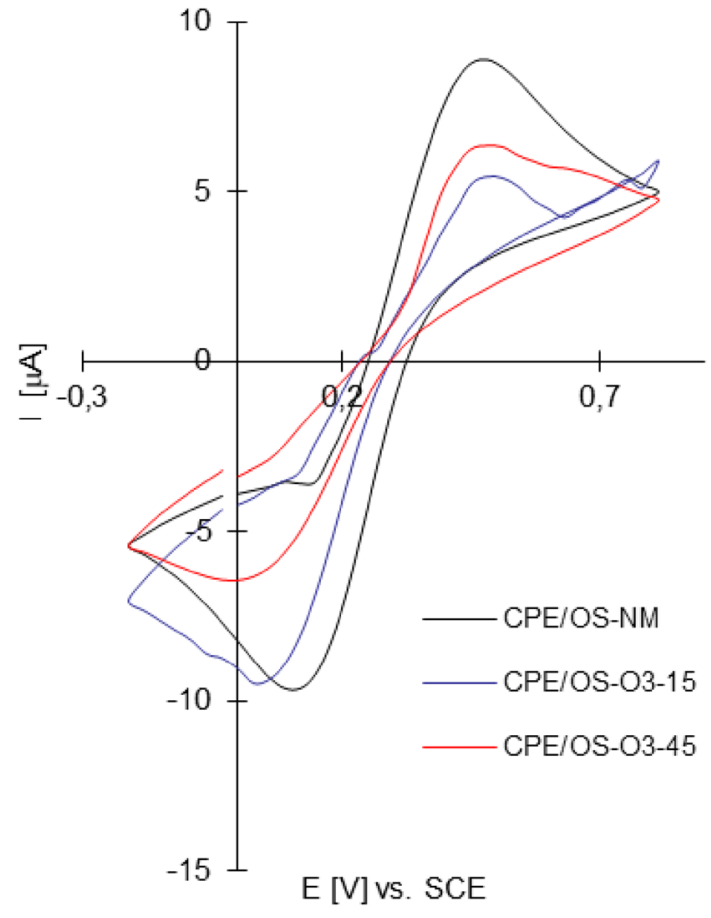

Fig. 4 The $\mathrm{CV}$ for the reduction of $1.0 \mathrm{mmol} / \mathrm{L}$ ferricyanide in $0.1 \mathrm{~mol} / \mathrm{L} \mathrm{KCl}$ at a carbon paste electrode modified with $10 \%$ of: OS-NM, OS-O3-15 and OS-O3-45 (scan rate $=100 \mathrm{mV} / \mathrm{s}$ )

where: $A$ - the area of the electrode $\left(\mathrm{cm}^{2}\right), n$-the number of electrons participating in the reaction (equal to 1 ), $D$ - the diffusion coefficient of the molecule in solution, $C$ - the concentration of the probe molecule in the solution $(2 \mathrm{mmol} / \mathrm{L})$ and $\nu$ - the scan rate $(\mathrm{V} / \mathrm{s})$.

The redox couple of $\mathrm{Fe}(\mathrm{CN})_{6}{ }^{3} / \mathrm{Fe}(\mathrm{CN})_{6}{ }^{4-}$ appeared to vary with the use of different electrodes. Based on the results presented in Fig. 4 the value of the active electrode area was found to be $0.145 \mathrm{~cm}^{2}, 0.102 \mathrm{~cm}^{2}$ and $0.083 \mathrm{~cm}^{2}$ for OS-NM, OS-O3-15 and OS-O3-45, respectively.

The influence of the accumulation time on the peak current was also determined. Accumulation time was varied from $1 \mathrm{~min}$ to $10 \mathrm{~min}$ and the corresponding current value was measured using one concentration of 4-CP $(0.1 \mathrm{mmol} / \mathrm{L})$. The peak current increased with the increase of accumulation time up to about 4 min and then becomes stable. For further research, 5 min were selected as the optimal accumulation time. The possible memory effect of the CPEs was also examined. To evaluate the memory effect of the electrode the measurements were performed in the sequence of high-to-low 4-CP concentration ( 0.5 and $0.05 \mathrm{mmol} / \mathrm{L}$ ). The signal response showed good repeatability. No memory effect was observed.

The effect of scan rate $(10-100 \mathrm{mV} / \mathrm{s})$ on the peak current and peak potential of 4-CP was evaluated. The scan rate increased with increasing anodic peak current. The anode current recorded at a potential of about $+0.75 \mathrm{~V}$ vs. SCE 


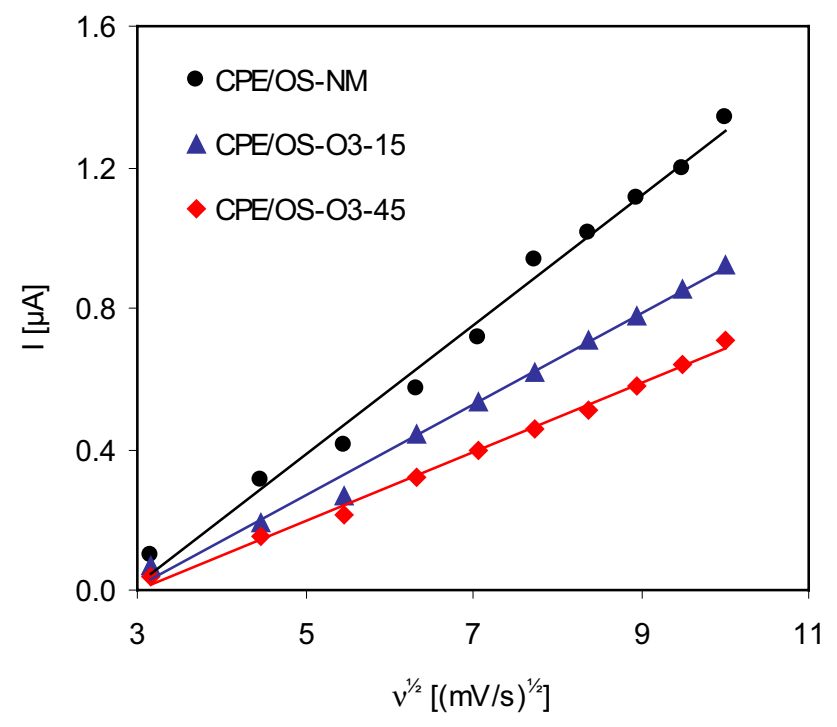

Fig. 5 Plot of I vs. $\nu^{1 / 2}$ for the oxidation of 4-chlorophenol at carbon paste electrodes modified with: OS-NM, OS-O3-15 and OS-O3-45

increased linearly with an increase of square root of scan rate as shown in Fig. 5. The values of the $R^{2}$ for the anodic peaks were $0.989 ; 0.993$ and 0.994 for OS-NM, OS-O3-15 and OS-O3-45, respectively. The logarithm of the peak current vs. logarithm of the scan rate suggested that the oxidation process is predominantly diffusion-controlled.

The oxidation process of the 4-CP on the CPE occurred at the potential value of approximately $+0.82 \mathrm{~V}$ vs. SCE, and only one peak appeared. The current corresponding to the peak oxidation of 4-CP increased with increase in the active area of the electrode and/or with increase in the

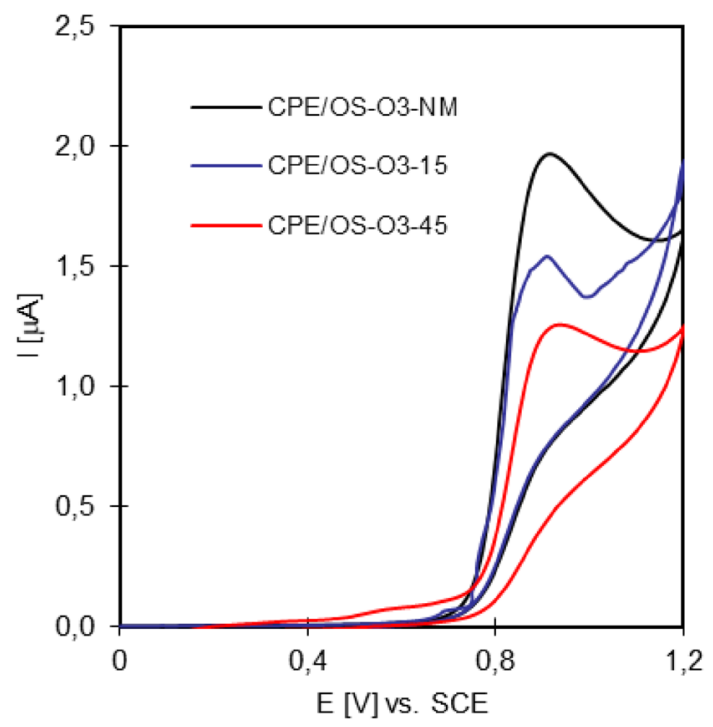

Fig. 6 The CV curve recorded in $0.5 \mathrm{mmol} / \mathrm{L} 4-\mathrm{CP}$ for CPEs modified with OS-NM, OS-O3-15 and OS-O3-45 adsorption capacity of the modifier used (CPE/OS-O3$45<$ CPE/OS-O3-15 < CPE/OS-NM). The measured peak currents were strongly dependent on oxidation of activated carbons and correlated with the 4-CP adsorption efficiency. The results are presented in Fig. 6.
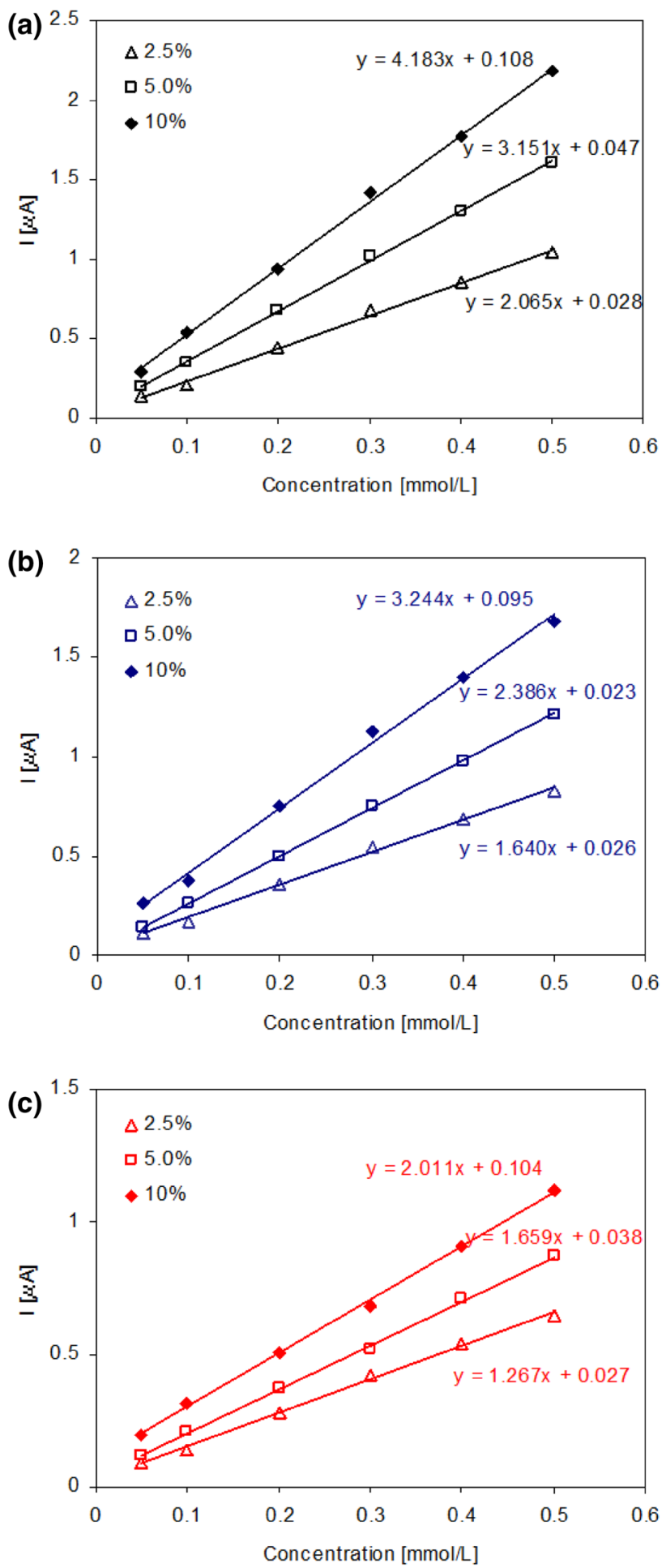

Fig. 7 Peak currents from CV for CPEs modified by adding various quantity of the materials: a OS-NM, b OS-O3-15 and c OS-O3-45 
Table 6 Comparison for the detection of 4-CP at different electrodes

\begin{tabular}{lll}
\hline Electrode & LOD $(\mu \mathrm{mol} / \mathrm{L})$ & References \\
\hline CPE/graphite & 79.7 & This study \\
CPE/OS-O3-45 & 4.91 & This study \\
CPE/OS-O3-15 & 3.06 & This study \\
CPE/OS-NM & 2.38 & This study \\
expanded graphite-epoxy electrode & 20.0 & Pop et al. 2008 \\
GCE modified with horseradish peroxidase & 15.2 & Zhang et al. 2012 \\
CNT/Pt nanoparticles/rhodamine B modified GCE & 3.70 & Zhu et al. 2018 \\
SBA-15-NH ${ }_{2}$ modified CPE & 1.40 & Deryło-Marczewska et al. 2016 \\
MWCNT-Ni(OH) ${ }_{2}$ modified GCE & 0.50 & Zolgharnein et al. 2013 \\
SBA-15 modified CPE & 0.40 & Deryło-Marczewska et al. 2016 \\
MWCNT/Au nanoparticle nanocomposite modified GCE & 0.11 & Wang et al. 2016 \\
rGO-Pt nanohybrid - modified GCE & 0.05 & Sun et al. 2018 \\
montmorillonite modified CPE & 0.02 & Yang et al. 2008 \\
\hline
\end{tabular}

GCE glassy carbon electrode
Figure 7 shows the effect of the amount of modifier added $(2.5,5.0$ and $10 \% \mathrm{~m} / \mathrm{m})$ on the $4-\mathrm{CP}$ peak current in the studied concentration range of $0.05-0.5 \mathrm{mmol} / \mathrm{L}$. The linearity of the methods was tested, the calibration plots were constructed by plotting peak current against 4-CP concentration and the plots were fitted by least-squares linear regression analysis. On the basis of the obtained results, it can be concluded that increase in the addition of the material (from 2.5 to $10 \%$ by weight) results in an increase in the oxidation peak height. The oxidation potential occurs at a value of approximately $0.81 \mathrm{~V}$. For comparison, linearity of the bare $\mathrm{CPE} /$ graphite was investigated under the same experimental conditions and the equation for regression line was $y=0.12 x-0.004\left(R^{2}=0.987\right)$. Compared to unmodified (CPE/graphite) electrode, it can be stated that even a relatively small addition of a modifier to $\mathrm{CPE}$ gives significant effects and increases the sensitivity of electroanalytical methods. The limit of detection (LOD) was determined using the following equation:

$\mathrm{LOD}=\frac{3 \times \mathrm{SD}_{\text {blank }}}{\mathrm{a}}$

where $S D_{\text {blank }}$ is the standard deviation of the blank and $a$ is the slope of the calibration curve $(\mathrm{y}=a \mathrm{x}+b)$. The best sensitivity was observed for the carbon paste electrode modified with OS-NM; the LOD was found to be $2.38 \mu \mathrm{mol} / \mathrm{L}$ and was over 30 times lower than for the bare (graphite) electrode (Table 6). Compared with other electrodes and electrochemical sensors (Table 6), the cheap and facile fabricated CPEs exhibited relatively good sensitivity. The sensitivity of these methods is comparable to, or slightly worse than those of electrochemical methods for 4-CP detection described by others. However, the limit of detection for 4-CP shows worse sensitivity compared with advanced techniques, such as HPLC but that requires time-consuming sample preparation and using organics. The LOD of 4-CP in HPLC was 0.006 mg/L (Higashi 2017), while in HeadspaceSPME was $0.23 \mu \mathrm{g} / \mathrm{mL}$ (Djozan and Bahar 2003).

\section{Conclusions}

The tested activated carbons (OS-NM, OS-O3-15 and OS-O3-45) showed significant differences in the surface chemistry and only low differences in the porous structure. The 4-CP was adsorbed better on the non-oxidized activated carbon (OS-NM) than on the ozone modified carbons. The 4-CP adsorption efficiency decreased in order OS-NM > OS-O3-15>OS-O3-45 and was strongly correlated with the increase in the content of oxygen functional groups on the adsorbent surface and also with the reduction of the specific surface area of activated carbons. The activated carbons were used for the modification of the CPEs for the detection of the 4-CP using the cyclic voltammetry. The prepared CPEs exhibited relatively good linearity and sensitivity, much better than the unmodified (graphite) electrode. The electrode response was correlated with the amount of modifier added as well as with the physicochemical properties of the activated carbons. The measured peak currents were strongly dependent on oxidation of activated carbons and correlated with the 4-CP adsorption efficiency, suggesting that the electrochemical oxidation of 4-CP on the CPE surface is a typical adsorption-controlled process.

Open Access This article is distributed under the terms of the Creative Commons Attribution 4.0 International License (http://creativeco mmons.org/licenses/by/4.0/), which permits unrestricted use, distribution, and reproduction in any medium, provided you give appropriate credit to the original author(s) and the source, provide a link to the Creative Commons license, and indicate if changes were made. 


\section{References}

Álvarez, P.M., García-Araya, J.F., Beltrán, F.J., Masa, F.J., Medina, F.: Ozonation of activated carbons: effect on the adsorption of selected phenolic compounds from aqueous solutions. J. Colloid Interf. Sci. 283, 503-512 (2005)

Chen, X., Paul, R., Dai, L.: Carbon-based supercapacitors for efficient energy storage. Natl. Sci. Rev. 4, 453-489 (2017)

Dąbrowski, A., Podkościelny, P., Hubicki, Z., Barczak, M.: Adsorption of phenolic compounds by activated carbon-a critical review. Chemosphere 58, 1049-1070 (2005)

Deryło-Marczewska, A., Buczek, B., Świątkowski, A.: Effect of oxygen surface groups on adsorption of benzene derivatives from aqueous solutions onto active carbon samples. Appl. Surf. Sci. 257, 9466-9472 (2011)

Deryło-Marczewska, A., Zienkiewicz-Strzałka, M., Skrzypczyńska, K., Świątkowski, A., Kuśmierek, K.: Evaluation of the SBA-15 materials ability to accumulation of 4-chlorophenol on carbon paste electrode. Adsorption 22, 801-812 (2016)

Djozan, D., Bahar, S.: Monitoring of phenol and 4-chlorophenol in petrochemical sewage using solid-phase microextraction and capillary gas chromatography. Chromatographia 58, 637-642 (2003)

Foo, K.Y., Hameed, B.H.: Detoxification of pesticide waste via activated carbon adsorption process. J. Hazard. Mater. 175, 1-11 (2010)

Gai, P.L., Billinge, B.H.M., Brown, A.M.: Microstructure of carbons. Carbon 27, 41-53 (1989)

Ghaedi, M., Naderi, S., Montazerozohori, M., Taghizadeh, F., Asghar, A.: Chemically modified multiwalled carbon nanotube carbon paste electrode for copper determination. Arab. J. Chem. 10(2), S2934-S2943 (2017)

Hamdaoui, O., Naffrechoux, E.: Modeling of adsorption isotherms of phenol and chlorophenols onto granular activated carbon. Part I. Two-parameter models and equations allowing determination of thermodynamic parameters. J. Hazard. Mater. 147, 381-394 (2007)

Hameed, B.H., Chin, L.H., Rengaraj, S.: Adsorption of 4-chlorophenol onto activated carbon prepared from rattan sawdust. Desalination 225, 185-198 (2008)

Higashi, Y.: Simple HPLC-UV analysis of phenol and its related compounds in tap water after pre-column derivatization with 4-nitrobenzoyl chloride. Methods Instrum 7, 18-28 (2017)

Jesionowski, T., Klapiszewski, Ł, Milczarek, G.: Kraft lignin and silica as precursors of advanced composite materials and electroactive blends. J. Mater. Sci. 49, 1376-1385 (2014a)

Jesionowski, T., Klapiszewski, Ł, Milczarek, G.: Structural and electrochemical properties of multifunctional silica/lignin materials. Mater. Chem. Phys. 147, 1049-1057 (2014b)

Jian, X., Liu, S., Gao, Y., Tian, W., Jiang, Z., Xiao, X., Tang, H., Yin, L.: Carbon-based electrode materials for supercapacitor: progress, challenges and prospective solutions. J. Electrical Eng. 4, 75-87 (2016)

Kuśmierek, K., Świątkowski, A.: The influence of an electrolyte on the adsorption of 4-chlorophenol onto activated carbon and multi-walled carbon nanotubes. Desalination Water Treat. 56, 2807-2816 (2015)

Kuśmierek, K., Sankowska, M., Skrzypczyńska, K., Świątkowski, A.: The adsorptive properties of powdered carbon materials with a strongly differentiated porosity and their applications in electroanalysis and SPME-GC. J. Colloid Interf. Sci. 446, 91-97 (2015)

Kuśmierek, K., Świątkowski, A., Skrzypczyńska, K., Błażewicz, S., Hryniewicz, J.: The effects of the thermal treatment of activated carbon on the phenols adsorption. Korean J. Chem. Eng. 34(4), 1081-1090 (2017)
Li, F., Li, J., Feng, Y., Yang, L., Du, Z.: Electrochemical behavior of graphene doped carbon paste electrode and its application for sensitive determination of ascorbic acid. Sens Actuators B 157, 110-114 (2011)

Lorenc-Grabowska, E., Gryglewicz, G., Machnikowski, J.: p-Chlorophenol adsorption on activated carbons with basic surface properties. Appl. Surf. Sci. 256, 4480-4487 (2010)

Mattevi, C., Eda, G., Agnoli, S., Miller, S., Mkhoyan, K.A., Celik, O., Mastrogiovanni, D., Granozzi, G., Garfunkel, E., Chhowalla, M.: Evolution of electrical, chemical, and structural properties of transparent and conducting chemically derived graphene thin films. Adv. Func. Mater. 19, 2577-2583 (2009)

Parvin, M.H.: Graphene paste electrode for detection of chlorpromazine. Electrochem. Commun. 13, 366-369 (2011)

Polovina, M., Babic, B., Kaluderovic, B., Dekanski, A.: Surface characterization of oxidized activated carbon cloth. Carbon $\mathbf{3 5}$, 1047-1052 (1997)

Pop, A., Manea, F., Radovan, C., Corb, I., Burtica, G., Malchev, P., Picken, S., Schoonman, J.: Determination of 4-chlorophenol using two types of graphite-based composite electrodes. Rev. Roum. Chim. 53(8), 623-628 (2008)

Rodriguez-Reinoso, F.: The role of carbon materials in heterogeneous catalysis. Carbon 36(3), 159-175 (1998)

Salame, I.I., Bandosz, T.J.: Role of surface chemistry in adsorption of phenol on activated carbons. J. Colloid Interf. Sci. 264, 307-312 (2003)

Skrzypczyńska, K., Kuśmierek, K., Świątkowski, A.: Carbon paste electrodes modified with various carbonaceous materials for the determination of 2,4-dichlorophenoxyacetic acid by differential pulse voltammetry. J. Electroanal. Chem. 766, 8-15 (2016)

Smarzewska, S., Pokora, J., Leniart, A., Festinger, N., Ciesielski, W.: Carbon paste electrodes modified with graphene oxides-comparative electrochemical studies of thioguanine. Electroanalysis 28, 1562-1569 (2016)

Stankovich, S., Dikin, D.A., Piner, R.D., Kohlhaas, K.A., Kleinhammes, A., Jia, Y., Wu, Y., Nguyen, S.B.T., Ruoff, R.S.: Synthesis of graphene-based nanosheets via chemical reduction of exfoliated graphite oxide. Carbon 45, 1558-1565 (2007)

Sun, Q., Li, J., Le, T., Zhang, L.: A novel voltammetric sensor based on reduced graphene oxide-platinum nanohybrid-modified electrode for facile and effective determination of 4-chlorophenol in real water samples. Bull. Korean Chem. Soc. 39, 611-617 (2018)

Švancara, I., Vytřas, K., Barek, J., Zima, J.: Carbon paste electrodes in modern electroanalysis. Crit. Rev. Anal. Chem. 31(4), 311-345 (2001)

Valdes, H., Sanchez-Polo, M., Rivera-Utrilla, J., Zaror, C.A.: Effect of ozone treatment on surface properties of activated carbon. Langmuir 18, 2111-2116 (2002)

Wang, L., Sun, Q., Liu, Y., Lu, Z.: Voltammetric determination of 4-chlorophenol using multiwall carbon nanotube/gold nanoparticle nanocomposite modified glassy carbon electrodes. RSC Adv. 6, 34692-34698 (2016)

Wong, A., Scontri, M., Materon, E.M., Lanza, M.R.V., Sotomayor, M.D.P.T.: Development and application of an electrochemical sensor modified with multi-walled carbon nanotubes and graphene oxide for the sensitive and selective detection of tetracycline. J. Electroanal. Chem. 757, 250-257 (2015)

Yagub, M.T., Sen, T.K., Afroze, S., Ang, H.M.: Dye and its removal from aqueous solution by adsorption: a review. Adv. Colloid Interf. Sci. 209, 172-184 (2014)

Yang, H., Zheng, X., Huang, W., Wu, K.: Modification of montmorillonite with cationic surfactant and application in electrochemical determination of 4-chlorophenol. Colloids Surf. B 65, 281-284 (2008) 
Zaidi, S.A.: Graphene: a comprehensive review on its utilization in carbon paste electrodes for improved sensor performances. Int. J. Electrochem. Sci. 8, 11337-11355 (2013)

Zhang, Y., Zhang, J., Wu, H., Guo, S.: Glass carbon electrode modified with horseradish peroxidase immobilized on partially reduced graphene oxide for detecting phenolic compounds. J. Electroanal. Chem. 681, 49-55 (2012)

Zhang, W., Zhu, S., Luque, R., Han, R., Hu, S., Xu, L.: G.: Recent development of carbon electrode materials and their bioanalytical and environmental applications. Chem. Soc. Rev. 45, 715-752 (2016)

Zhu, X., Zhang, K., Wang, D., Zhang, D., Yuan, X., Qu, J.: Electrochemical sensor based on hydroxylated carbon nanotubes/ platinum nanoparticles/rhodamine B composite for simultaneous determination of 2,4,6-trichlorophenol and 4-chlorophenol. J. Electroanal. Chem. 810, 199-206 (2018)

Zima, J., Švancara, I., Barek, J., Vytřas, K.: Recent advances in electroanalysis of organic compounds at carbon paste electrodes. Crit. Rev. Anal. Chem. 39, 204-227 (2009)

Zolgharnein, J., Shariatmanesh, T., Babaei, A.: Multivariate optimization of a new 4-chlorophenol sensor fabricated by modification of glassy carbon electrode using $\mathrm{Ni}(\mathrm{OH})_{2}$ nanoparticles-carbon nanotubes (NNH-MWCNTs). Sens. Actuators B 186, 536-544 (2013) 